\title{
PET Imaging of the Human Nicotinic Cholinergic Pathway in Atherosclerosis
}

\author{
Matthias Bauwens $^{1,2}$ - Felix M. Mottaghy ${ }^{1,3}$ - Jan Bucerius ${ }^{1,3,4}$ \\ Published online: 17 July 2015 \\ (C) The Author(s) 2015. This article is published with open access at Springerlink.com
}

\begin{abstract}
During the past years, non-neuronal vascular nicotinic acetylcholine receptors (nAChRs) increasingly have gained interest in cardiovascular research, as they are known to mediate the deleterious effects of nicotine and nitrosamines, components of tobacco smoke, on the vasculature. Because smoking is a major risk factor for the development of atherosclerosis, it is obvious that understanding the pathophysiologic role of nAChRs in the atherosclerotic disease process, as well as in the development of new diagnostic and therapeutic nAChR-related options, has become more important. Accordingly, we briefly summarize the pathophysiologic role of vascular nAChRs in the atherosclerotic disease process. We also provide an overview of currently available nAChR positron emission tomography (PET) tracers and their performance in the noninvasive imaging of vascular nAChRs, as well as potential nAChR PET tracers that might be an option for vascular nAChR PET imaging in the future.
\end{abstract}

This article is part of the Topical Collection on Nuclear Cardiology

Jan Bucerius

jan.bucerius@mumc.nl

1 Department of Nuclear Medicine, Maastricht University Medical Center (MUMC+), Maastricht, The Netherlands

2 Department of Human Biology, School for Nutrition, Toxicology, and Metabolism (NUTRIM), Maastricht University Medical Center (MUMC+), Maastricht, The Netherlands

3 Cardiovascular Research Institute Maastricht (CARIM), Maastricht University Medical Center (MUMC+), Maastricht, The Netherlands

4 Cardiovascular Research Institute Maastricht (CARIM), Maastricht University Medical Center (MUMC+), P. Debyelaan 25, 6229 HX Maastricht, The Netherlands
Keywords Nicotinic acetylcholine receptors · Positron emission tomography $\cdot$ Atherosclerosis

\section{Introduction}

Interest in non-neuronal vascular nicotinic acetylcholine receptors (nAChRs) has been increasing in cardiovascular research because they are known to mediate the deleterious effects of nicotine and nitrosamines, components of tobacco smoke, on the vasculature. Smoking is a major, if not the greatest, risk factor for the development of atherosclerosis. Therefore, understanding the pathophysiologic role of nAChRs in the atherosclerotic disease process, and consequently, the development of new diagnostic and therapeutic nAChR-related options, has become more important. The first steps in that direction-development of new noninvasive imaging strategies for nAChRs by means of positron emission tomography (PET) - have been taken and, along with the pathophysiologic role of nAChRs in atherosclerosis, are described in this review article.

\section{Atherosclerosis}

The clinical consequences of atherosclerosis - myocardial infarction and stroke - remain the most common causes of death in Europe and worldwide [1-3]. It is well known that atherosclerotic progression and severity are linked to many clinical risk factors, including hyperlipidemia, diet, diabetes, obesity, hypertension, and nicotine abuse.

Atherosclerosis reflects a pathologic process in the arterial wall, where endothelial injury results in accumulation of lipids and inflammatory cells in the intima [1, 
$4 \bullet \bullet$. The blood-derived monocytes differentiate into macrophages, which express scavenger receptors, allowing them to ingest oxidized lipids and become foam cells $[1,5]$. Early atherosclerotic plaques originate as fatty streaks, which are lipid-filled macrophage foam cells consisting of fat, cholesterol, and other biologic components $[4 \cdot \bullet]$. As these lesions further expand, foam cell apoptosis and necrosis result in continuing accumulation of lipids and necrotic debris. This process leads to the development of a highly thrombogenic lipid core and an expansion of the plaque within the arterial wall. In addition, via various signaling cascades, soluble factors are released, mediating platelet adhesion as well as proliferation and migration of vascular smooth muscle cells (VSMCs) from the tunica media to the intima. The VSMCs compose a stabilizing, collagen-rich, fibrous cap, which covers the lipid core, resulting in highly vascularized stable or unstable vulnerable plaques $[1,6]$.

\section{Nicotinic Cholinergic Pathway}

During recent years, cardiovascular researchers became increasingly interested in nAChRs, the most frequent cholinergic receptors in the central nervous system (CNS), as non-neuronal nAChRs are known to mediate the deleterious effects of nicotine and nitrosamines, components of tobacco smoke, on the vasculature. Because smoking is a major risk factor for the development of atherosclerosis and consequently, stroke and myocardial infarction, it has become clear that understanding the pathophysiologic role of nAChRs in the atherosclerotic disease process, as well as the development of new diagnostic and therapeutic nAChR-related options, is more important than ever. In this review, we focus mainly on the potential of noninvasive imaging of nAChRs by means of PET combined with CT (PET/CT) or MRI (PET/MRI) not on the physiologic or pathophysiologic role of vascular nAChRs in cardiovascular disease; however, we provide a brief summary on the physiology and proatherogenic effects of nAChRs in the vasculature $[4 \cdot \bullet, 7]$.

nAChRs are a heterogeneous family of ligand-gated transmembrane ion channel receptors that mediate fast synaptic transmission [8-11]. They work as a regulator of excitatory neurotransmission, and nAChR activity in the CNS has been found to regulate physiologic functions such as sleep, fatigue, arousal, central processing of pain, and cognitive functions [8, 10]. From a pathophysiologic point of view, nAChRs were identified as contributing to the pathogenesis of several diseases, including myasthenia gravis, Alzheimer's disease, and
Parkinson's disease $[8,10,12]$. This discovery led to the development of PET-feasible ${ }^{18} \mathrm{~F}$-labeled radiotracers for noninvasive diagnosis of these neurodegenerative disorders [13-15].

\section{Non-neuronal Vascular nAChRs}

It is now known that nAChRs are expressed ubiquitously in almost all cells in the blood vessels. There, these vascular nAChRs accelerate the atherogenic process [4••]. The structure of non-neuronal $n A C h R s$ such as vascular $n A C h R s$ closely resembles that found in CNS nAChRs: a pentamer composed of distinct subunits arranged tightly around a central pore [7]. So far, 12 different nAChR subunits, $\alpha 2$ to $\alpha 10$ and $\beta 2$ to $\beta 4$ have been identified that can form heteromeric nAChRs: for example, $\alpha 4 \beta 2$ nAChRs. In contrast, the homomeric receptors (e.g., $\alpha 7$-nAChRs) are made up of five $\alpha$-subunits.

nAChRs have been found on human VSMCs $(\alpha 2, \alpha 3, \alpha 4$, $\alpha 5, \alpha 7, \alpha 10)$; human aortic endothelial cells $(\alpha 3, \alpha 5, \alpha 7$, $\alpha 10, \beta 2, \beta 3, \beta 4)$; human platelets $(\alpha 7)$; human mononuclear leukocytes $(\alpha 7, \beta 2)$; human macrophages $(\alpha 1, \alpha 7, \alpha 10)$; B lymphocytes $(\alpha 3, \alpha 4, \alpha 5, \alpha 7)$; and T lymphocytes $(\alpha 3, \alpha 4$, $\alpha 7, \beta 2, \beta 4)[4 \bullet \bullet, 7,10,16-19]$.

The endogenous ligand for nAChRs is acetylcholine $(\mathrm{ACh})$; however, nicotine and tobacco-specific nitrosamines (e. g., NNK [4-(methylnitrosamino)-1-(3-pyridyl)-1-butanone], NNN [N0-nitrosonornicotine], DEN [N-diethylnitrosamine]) also are high-affinity nAChR ligands $[4 \cdot \bullet]$. Binding of the ligand to the receptor leads to a conformational change in the nAChR, resulting in opening of the ion channel and transmission of the signals. Charged amino acids line the central pore and select the ions that pass through the channel $[4 \cdot \bullet]$.

\section{nAChR-Mediated Atherogenic Effects}

The non-neuronal nicotinic cholinergic pathway regulates several components of atherogenesis, including inflammation, VSMC phenotype, proliferation, migration, and plaque neovascularization $[4 \cdot \bullet]$. The latter process is characterized by a network of capillaries, which originates from the adventitial vasa vasorum and extends into the intimal layer of atherosclerotic lesions $[4 \cdot \bullet]$.

NNK, a tobacco carcinogen and high-affinity ligand to nAChRs as described earlier, appears to cause endothelial cell apoptosis $[4 \bullet \bullet, 20]$. However, these findings are debated, as other groups found NNK to facilitate angiogenesis in lung and gastric cancer [21, 22]. Nicotine promotes chemotaxis and migration of rat and human VSMCs, as well as preventing VSMCs from undergoing apoptosis induced by serum deprivation, suggesting that growth and migration of VSMCs are 
enhanced by both these pathways [16, 23-27]. Heeschen et al. [28] investigated the effect of nicotine on VSMC migration, proliferation, growth, and neovascularization of advanced atherosclerotic plaques in mice and found a significantly larger median plaque area and a higher percentage of vascularized plaques in nicotine-treated mice compared with a control group. Their results indicated a nicotine-related stimulation of plaque growth related to increasing plaque neovascularization rather than VSMC proliferation [28, 29]. As mentioned earlier, nicotine stimulates VSMC migration depending on nAChR activity [16, 24, 25, 30]. Important signaling pathways that contribute to this nAChR-mediated VSMC migration are elevation of the early growth response gene 1 (Erg-1), increased calcium influx, activation of EGFR, increased telomerase activity, and phosphorylation of Ets-like gene 1 [25, 30, 31]. In addition, nicotine also was found to upregulate levels of proinflammatory cytokines, i.e., IL-6, MCP-1, and NF- $\mathrm{kB}$, in human aortic VSMCs [32].

Nicotine induces the production of growth factors such as TGF- $\alpha$, TGF- $\beta$, PDGF-BB, VEGF, and FGF-2 $[25,33$, 34]. These growth factors were shown to stimulate VSMC proliferation (PDGF-BB, TGF- $\alpha$, and FGF-2) and to promote the migration of human VSMCs and plaque neovascularization (VEGF) [6, 33, 34]. They also cause contractile-to-synthetic transition, cytoskeletal remodeling, enhanced proliferation, and migration of VSMCs - pathways that facilitate formation of the intimal lesions characteristic of atherosclerosis (PDGF-BB) [6, 33, 34]. Furthermore, endothelial permeability appears to be enhanced by increased expression of growth factors. This process also is known to contribute to plaque neovascularization and atherosclerotic progression $[4 \bullet \bullet, 35,36]$.

As described earlier, nAChRs are found on several immune cells. The influx of these immune cells, including macrophages, into the arterial wall is known to contribute to atherosclerotic plaque formation [37]. It therefore is likely that nicotine or other stimulating agents act on these immune cells and also on endothelial progenitor cells to facilitate neovascularization of plaques as well as thrombosis [4••]. Nicotine enhances the adhesion of human microvascular endothelial cells to monocytes, a process stimulated by upregulation of the cytokines TNF- $\alpha$ and IL- $\beta$ [4••, 17]. Furthermore, Aicher et al. [38] showed that nicotine caused a sevenfold increase in proinflammatory cytokine IL-12 and IL10 levels in human dendritic cells compared with untreated controls [38]. This upregulation was mediated via $\alpha 7-n A C h R s$ on the dendritic cells. The activation of dendritic cells by nicotine augments their capacity to stimulate $\mathrm{T}$ cell proliferation and, as mentioned earlier, to secrete cytokines. Both these pathways may contribute significantly to the proatherogenic effects of nicotine.

\section{PET Imaging of Vascular nAChRs}

PET is the most advanced technique for noninvasive molecular imaging in vivo [39-42]. It allows threedimensional quantitative detection of the distribution of radiolabeled ligands with high resolution and sensitivity. PET thereby provides functional images of biochemical and physiologic processes in different organ systems $[40,43]$. This advanced nuclear medicine technique has been integrated into clinical routine for in vivo imaging mainly in oncology but also in cardiology and neurology and for assessing inflammation [44]. Furthermore, PET is considered a highly sophisticated device for experimental animal research and has been proven to facilitate the translational process in the development of new radiotracers [40, 45, 46]. Clinical PET cameras are now available with a spatial resolution of about 2 to $3 \mathrm{~mm}$, allowing the investigation of radioligand distribution even within small target tissues in both animals and humans [40, 47, 48].

Today, almost all clinical PET systems are equipped with $\mathrm{CT}$ within one device, allowing anatomic correlation of the PET findings and therefore the combination of functional (PET) and morphologic (CT) imaging in one session. Whereas "PET-only" systems are now quite rare, the newest development involves hybrid PET/MRI scanners. This challenging imaging technique combining PET and MRI has been used in routine clinical practice for the past few years and has shown much promise in further broadening the spectrum of indication for hybrid functional and morphologic noninvasive imaging.

PET imaging for nAChRs initially was used to evaluate cerebral nAChR distribution in patients with neurodegenerative disorders such as Alzheimer's and Parkinson's disease [13-15]. The first attempts focused on imaging cerebral $\alpha 4 \beta 2$-nAChRs, which were shown to be significantly reduced in both Alzheimer's and Parkinson's disease [15]. Along with further development of ${ }^{18} \mathrm{~F}$-labeled PET tracers for clinical imaging of cerebral $\alpha 4 \beta 2$-nAChRs, more recent approaches have focused on development and evaluation of $\alpha 7-\mathrm{nAChR}$ PET tracers, which are now available and awaiting further preclinical and clinical evaluation $[49,50 \bullet \bullet, 51-53$, $54 \bullet \bullet, 55]$.

In 2006, our group published the first attempts to image non-neuronal $\alpha 4 \beta 2$-nAChRs [56]. It is known that stimulation of the parasympathetic autonomic system decreases heart rate and cardiac contractility and that this pathway is mediated by acetylcholine acting 
on intracardiac ganglionic nAChRs and cardiac muscarinic acetylcholine receptors (mAChRs). Therefore, we aimed to assess the distribution of cardiac $\alpha 4 \beta 2$ nAChRs with a dedicated $\alpha 4 \beta 2$-nAChR PET ligand $\left(\left[{ }^{18} \mathrm{~F}\right]\right.$-2-fluoro-A85380) in humans. Furthermore, we attempted to evaluate whether the cardiac distribution of $\alpha 4 \beta 2$-nAChRs differs between healthy controls and patients with known Parkinson's disease or multiple system atrophy (MSA), as it already was demonstrated that cerebral distribution of these nAChRs is reduced in these patient populations.

Five healthy volunteers without cardiac disease and six patients with either Parkinson's disease or MSA without additional overt cardiac disease were evaluated with $\left[{ }^{18} \mathrm{~F}\right]$ 2-fluoro-A85380 PET imaging to assess cardiac parasympathetic innervation and the putative impact of both disorders thereon. Whole-body PET scans were performed on a Siemens PET/CT Biograph (Siemens, Erlangen, Germany) $75.4 \pm 6.7 \mathrm{~min}$ after intravenous injection of $371 \pm 58 \mathrm{MBq}$ of the tracer. The average count rate density of left ventricular regions of interest (ROIs) and a standard ROI in the right lung was measured in three consecutive slices, and heart-to-lung ratios were calculated consecutively in each volunteer and patient. Heart-to-lung ratios in the volunteer group did not differ from those in patients with Parkinson's disease or MSA ( $3.2 \pm 0.5$ vs. $3.2 \pm 0.8$ and $2.96 \pm 0.7$, respectively, mean $\pm \mathrm{SD} ; P=$ not significant for all) [56]. Based on the results of our study, we concluded that human cardiac nAChRs can be visualized and measured by $\left[{ }^{18} \mathrm{~F}\right]$-2-fluoro-A85380 PET scans in both cardiac-healthy subjects and patients with Parkinson's disease or MSA. Furthermore, these first results suggest no significant impact of either Parkinson's disease or MSA on cardiac nAChRs.

In a second step, we evaluated the feasibility of the $\left[{ }^{18} \mathrm{~F}\right]$-2-fluoro-A85380 PET tracer for imaging nonneuronal vascular $\alpha 4 \beta 2$-nAChRs in the same study population of five healthy controls and six patients with Parkinson's disease or MSA [57••]. Again, the aim was to determine whether this tracer could noninvasively image vascular $\alpha 4 \beta 2$-nAChRs in vivo in humans via PET and to investigate whether neurodegenerative disorders such as Parkinson's disease and MSA might have an impact on the vascular distribution of these nAChRs. Because of the pathophysiologic importance of nAChRs in atherosclerosis, which was mentioned earlier, proving the ability to noninvasively detect nAChRs in humans is of crucial relevance for the diagnostic and subsequent therapeutic approach in patients with atherosclerosis. We therefore quantified $\left[{ }^{18} \mathrm{~F}\right]$-2-fluoro-A85380 uptake in the ascending and descending aorta, the aortic arch, and the carotids in our aforementioned study population as the maximum target-to-background ratio (Fig. 1). The maximal standardized uptake value (SUV), single hottest segment, and percentage of active segments of $\left[{ }^{18} \mathrm{~F}\right]-2$ fluoro-A85380 uptake in the arteries also were assessed. We could clearly visualize the $\left[{ }^{18} \mathrm{~F}\right]-2$-fluoro-A85380 uptake, and the maximum target-to-background ratio uptake values corrected for the background activity of the tracer showed specific tracer uptake in the arterial walls. Significantly greater uptake values were found in the descending aorta. Comparison between volunteers and patients revealed significant differences, with lower $\left[{ }^{18} \mathrm{~F}\right]$-2-fluoro-A85380 uptake in the patient group when single arterial territories were compared but not when all arterial territories were pooled together [57••]. Our results clearly suggest that $\left[{ }^{18} \mathrm{~F}\right]$-2-fluoro-A85380 can provide specific information on the $\mathrm{nAChR}$ distribution in human arteries. Furthermore, the vascular nAChR density appears lower in patients with Parkinson's disease or MSA, indicating an impact of both neurodegenerative disorders on human arteries [57]. Currently, our group is carrying out studies in larger populations as well as in the experimental setting to further validate the approach of noninvasive in vivo imaging of vascular nAChRs, which will provide more detailed insights into the pathogenic role of nAChRs in the human vasculature [58].

Recently, Rötering et al. [54・•] evaluated a newly developed $\alpha 7$-nAChR PET tracer $\left(\left[{ }^{18} \mathrm{~F}\right] \mathrm{NS} 14490\right)$ preclinically in an experimental pig model. $\alpha 7$-nAChRs are an important molecular target in neuropsychiatry and oncology, but, as mentioned earlier, also play a crucial role in the pathophysiologic disease process in atherosclerosis. So far, the development of applicable highly specific radiotracers has been challenging because of comparatively low protein expression. One novel ligand that might be a feasible candidate for in vivo PET imaging of cerebral but also vascular $\alpha 7$-nAChRs is $\left[{ }^{18} \mathrm{~F}\right] \mathrm{NS} 14490$. This tracer was shown to yield reliable results in organ distribution studies and therefore was tested in a dynamic PET study in piglets. In this study by Rötering et al. [54••], PET measurements were performed in young pigs to investigate the metabolic stability and cerebral binding of $\left[{ }^{18} \mathrm{~F}\right] \mathrm{NS} 14490$ without and with administration of the $\alpha 7$ nAChR partial agonist NS6740 in baseline and blocking conditions. Dynamic time-activity curves were calculated for the frontal cortex, temporal lobe, parietal lobe, occipital lobe, hippocampus, striatum, cerebellum, thalamus, middle cortex, ventral cortex, midbrain, pons, colliculi, left carotid artery, and circle of Willis. In addition, to investigate the selectivity of $\alpha 7$-nAChR blockade in the cerebral vessels, SUV in the left carotid artery, and circle of Willis was calculated retrospectively (Fig. 2). Assuming complete blockade of the receptor by the partial agonist, the displacement indicated a specific binding potential of 


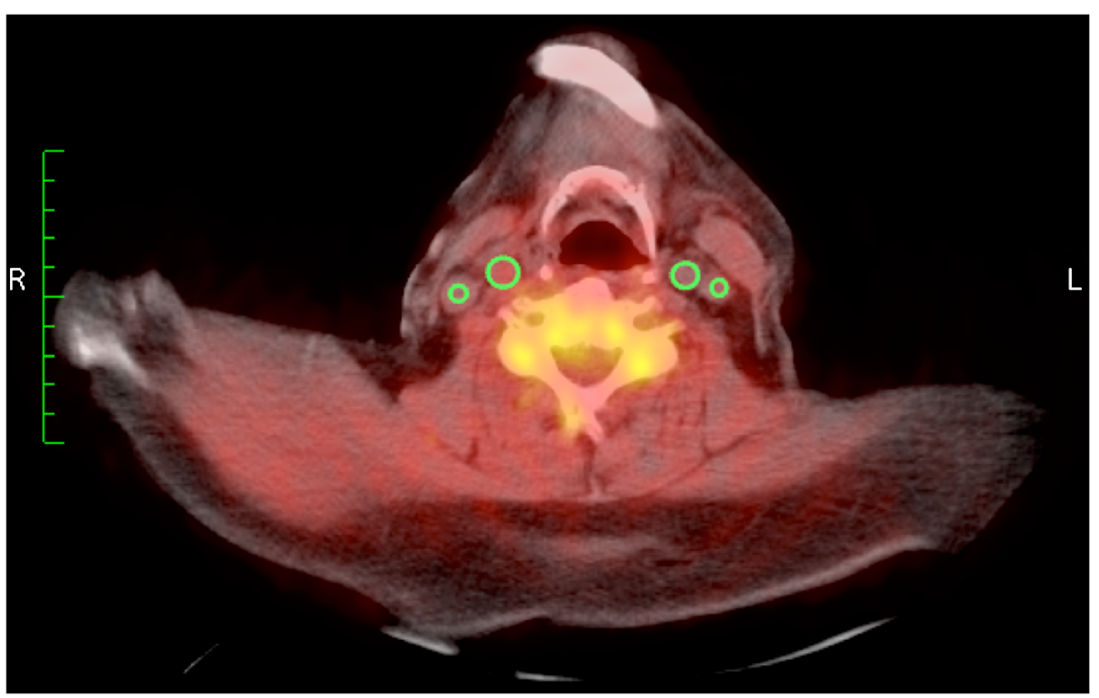

Fig. $1 \alpha 4 \beta 2$-nAChR PET/CT scan showing $\left[{ }^{18} \mathrm{~F}\right]-2$-fluoro-A85380 uptake in the right and left common carotid arteries (upper ROIs green) and in the right and left jugular veins (lower ROIs). On a visual basis, the fused PET/CT image shows higher uptake of the tracer in the two common carotids compared with the two veins, indicating a specific tracer uptake in the arteries. Furthermore, the right common carotid artery

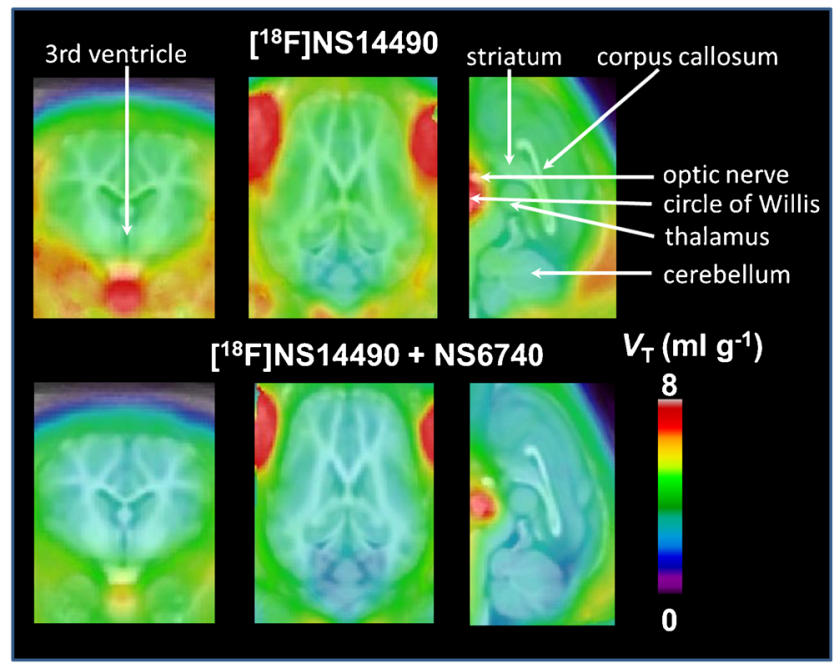

Fig. 2 Parametric maps of the distribution volume $\left(V_{\mathrm{T}}\right)$ of $\left[{ }^{18} \mathrm{~F}\right] \mathrm{NS} 14490$ in the brain of piglets. Animal studies were performed without blocked conditions (controls, upper row) and with pretreatment with the competitor NS6740 (blocked conditions, lower row). Parametric maps are projected onto a magnetic resonance atlas for the pig brain. Values represent the mean of control animals and animals with blocking. Based on the assumption of a complete blockade, the displacement of the $\alpha 7$ nAChR PET tracer by the competitor indicates a specific binding potential in the brain of living pigs, as well as evidence for specific binding in major brain arteries, such as the carotid arteries. The latter appears to enable the PET radiotracer $\left[{ }^{18} \mathrm{~F}\right] \mathrm{NS} 14490$ to specifically image $\alpha 7$ nAChRs in vulnerable plaques of diseased arterial vessels. Data are given in milliliters per gram [54••]. (With permission from: Rötering $\mathrm{S}$, Deuther-Conrad W, Cumming P, et al.: Imaging of $\alpha 7$ nicotinic acetylcholine receptors in brain and cerebral vasculature of juvenile pigs with [18F] NS14490. EJNMMI Research 2014, 4:43) [89] shows a higher uptake $\left(\mathrm{SUV}_{\max } 1.7\right.$ vs. $\mathrm{SUV}_{\max } 1.2$ in the left common carotid artery) compared with the left common carotid artery, whereas the uptake in the two jugular veins is almost identical (right $\mathrm{SUV}_{\text {mean }} 1.0 \mathrm{vs}$. left $S_{U V}$ mean 1.1), further indicating a specific arterial uptake of the PET tracer as well as a higher density of the $\alpha 4 \beta 2-n A C h R s$ in the right than in the left common carotid artery

$\left[{ }^{18} \mathrm{~F}\right] \mathrm{NS} 14490$ in the brain of living pigs, as well as evidence of specific binding in major brain arteries, such as the carotid arteries. The latter is tremendous because it appears to enable the PET radiotracer $\left[{ }^{18} \mathrm{~F}\right] \mathrm{NS} 14490$ to image $\alpha 7-n A C h R s$ in vulnerable plaques of diseased vessels [54••]. Within the next few months, a prospective study using the $\alpha 7$-nAChR PET tracer and the recently introduced hybrid PET/MRI technique will begin in patients with carotid artery disease requiring carotid surgery, further evaluating the potential of this PET tracer to image vascular $\alpha 7$-nAChR in atherosclerosis noninvasively.

\section{Current PET Tracers for $\alpha 4 \beta 2$ nAChRs}

The concept of imaging the $\alpha 4 \beta 2$ receptor, as described earlier, originally was designated for brain receptors. Consequently, several radioligands have been developed, which are discussed in the following text. Not all the tracers listed show high affinity, and even in those that do, it remains to be seen whether they are suitable for imaging vascular nAChRs, as brain studies generally require a different approach. For example, the lipophilicity of a radiopharmaceutical should be high enough to allow it to penetrate the blood-brain barrier (BBB) for imaging of brain receptors. However, this is not a requirement in peripheral imaging; in fact, the lipophilic character of a drug may even lead to slower blood clearance, preventing timely image acquisition protocols. On the other hand, a certain degree of metabolite formation is acceptable in 
brain receptor imaging, provided the radiometabolites themselves do not cross the BBB. In the periphery, of
11C-Nicotine
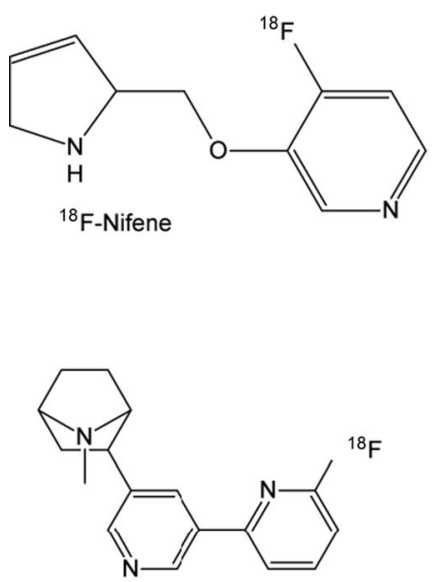

${ }^{18} \mathrm{~F}^{-} \mathrm{AZAN}$ course, metabolization of the radiopharmaceutical leads to poor image quality and interpretation.
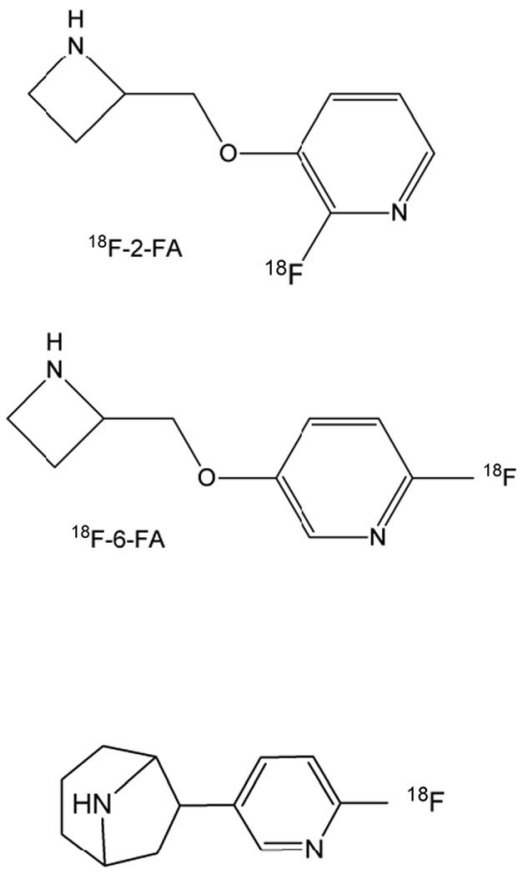

${ }^{18} \mathrm{~F}$-Flubatine<smiles>[18F]CCCCC#Cc1cncc(OCC2CCN2)c1</smiles>

${ }^{18} \mathrm{~F}-\mathrm{ZW}-104$

\section{$\left[{ }^{11} \mathrm{C}\right]-$ Nicotine}

$\left[{ }^{11} \mathrm{C}\right]$-Nicotine was one of the first radioligands used to image cerebral nicotine receptors [59-62]. The radiosynthesis is well-developed, with the latest publication reporting a $90 \%$ decay-corrected yield, $99 \%$ radiochemical purity, and 7- to $11-\mathrm{GBq} / \mu \mathrm{mol}-\mathrm{specific}$ activity. Sadly, however, this ligand shows low specific binding in combination with high nonspecific binding and is metabolized rapidly, rendering the tracer unsuitable for quantitative applications in human studies. This is a known disadvantage in brain studies but has a major impact on imaging applications in the vasculature, in which metabolites are an even greater complication.

\section{$\left[{ }^{18}\right.$ F $]$ Nifene}

$\left[{ }^{18} \mathrm{~F}\right]$ Nifene [(S)-3-((2,5-dihydro-1H-pyrrol-2-yl)methoxy)$2-\left[{ }^{18} \mathrm{~F}\right]$-fluoropyridine $]$ was synthesized and evaluated for the first time in an animal model in 2006 by Pichika et al. [63]. Since then, the same group reported an optimized radiosynthesis (with 6-12\% in-hand yield, 10-20\% decaycorrected) and more preclinical data, particularly in rats and rhesus monkeys [64, 65]. So far, their research has shown $\left[{ }^{18} \mathrm{~F}\right]$ nifene to have rapid brain kinetics and reasonable binding potential (1.7), whereas its binding in the brain (but not the cerebellum) could be displaced by nicotine, indicating specific binding to a nicotinergic receptor, presumably $\alpha 4 \beta 2$. Although some prior optimization must be done to fully characterize radiometabolites and their in vivo behavior, this tracer appears to be an available candidate for human studies in the near future.

\section{$\left[{ }^{18} \mathbf{F}\right] \mathbf{F A}$}

2- $\left[{ }^{18} \mathrm{~F}\right] \mathrm{FA}$ and 6- $\left[{ }^{18} \mathrm{~F}\right] \mathrm{FA}$ (respectively, (S)-3-(azetidin-2methyloxy)-2-[ $\left.{ }^{18} \mathrm{~F}\right]$ fluoropyridine and (S)-3-(azetidin- 
2methyloxy)-6- $\left[{ }^{18} \mathrm{~F}\right]$ fluoropyridine), also known as $2-\left[{ }^{18} \mathrm{~F}\right]-\mathrm{A}-$ 85380 and $6-\left[{ }^{18} \mathrm{~F}\right]-\mathrm{A}-85380$, can be synthesized with a high non-decay-corrected yield of about $50 \%$ [66]. Both are very polar compounds with a resulting moderate BBB permeation and slow brain uptake. In combination with the slow washout rates, requiring scanning up to 6-h post injection, these tracers are not optimal for brain research. They still are being used, however, owing greatly to their relatively good specific $\mathrm{nAChR}$ binding, and several publications have appeared both preclinically and clinically, even in the past few years. In comparing 2-FA with 6-FA, there is a general preference for 2-FA because of its lower toxicity ( $15 \mathrm{vs} .1 .8 \mu \mathrm{mol} / \mathrm{kg})$.

Also available is a single-photon emission CT (SPECT) version of the A-85380 tracer: $\left[{ }^{123} \mathrm{I}\right]-5-\mathrm{IA}-85380\left(\left[{ }^{123} \mathrm{I}\right]-5-\right.$ IA; $\left[{ }^{123} \mathrm{I}\right]-5$-iodo-3-[2(S)-azetidinylmethoxy]pyridine). This compound has properties necessary for in vivo imaging of nAChRs with SPECT, including high affinity (dissociation constant $[\mathrm{Kd}]=11 \mathrm{pmol} / \mathrm{L}$ ), rapid entry into the brain, low nonspecific binding, and minimal toxicity. However, it has the disadvantage of using an isotope suitable only for SPECT, with its intrinsic lower resolution and lack of good quantification possibilities, but like the ${ }^{18} \mathrm{~F}$-labeled versions, also shows a slow washout rate [67].

The slow clearance of $\left[{ }^{18} \mathrm{~F}\right] \mathrm{FA}$ from the blood (half-life, $6 \mathrm{~h}$ ) poses several challenges for vasculature imaging, as late scan times often are impractical (for patients) and less accurate (because of potential metabolite build-up). Similar ligands, such as $\left[{ }^{18} \mathrm{~F}\right]$ nifzetidine and $\left[{ }^{11} \mathrm{C}\right] \mathrm{MA}$, showed similarly slow kinetics, rendering this class of ligands feasible but suboptimal for human use $[63,64,68]$.

\section{$\left[{ }^{18} \mathrm{~F}\right] \mathrm{ZW}-104$}

$\left[{ }^{18} \mathrm{~F}\right] \mathrm{ZW}-104$ [(S)-3-(azetidin-2-ylmethoxy)-5-(6- $\left[{ }^{18} \mathrm{~F}\right]$ fluorohex1 -ynyl)pyridine] is a selective ligand for the $\beta 2$-containing nAChRs and has a better binding affinity profile than 2-FA [69]. Radiosynthesis is performed in two steps, followed by HPLC purification, and shows rather poor yields (3-5\%) and moderate specific radioactivity. Brain uptake in baboons is high and specific (demonstrated by the blocking effect of nicotine) and is better overall than that of $\left[{ }^{18} \mathrm{~F}\right] \mathrm{FA}$; however, it still is characterized by slow kinetics, especially during the washout.

\section{$\left[{ }^{18}\right.$ F $]$ AZAN- $\alpha$}

$\left[{ }^{18} \mathrm{~F}\right]$ AZAN was developed as an improvement over the 2- $\left[{ }^{18} \mathrm{~F}\right] \mathrm{FA}$ and $6-\left[{ }^{18} \mathrm{~F}\right] \mathrm{FA}$ ligands, aiming to increase brain uptake and washout kinetics while maintaining a high binding affinity $[70,71]$. The precursor currently is available commercially, and although the synthesis yield is similar to that of $\left[{ }^{18} \mathrm{~F}\right] \mathrm{FA}$ (around $50 \%$ ), the one-step synthesis is less complex than the two-step synthesis of $\left[{ }^{18} \mathrm{~F}\right] \mathrm{FA}$ compounds (although HPLC purification still is required), making the radiosynthesis more robust.
After initial trials in baboons confirming specificity and rapid kinetics (90-min scan time is sufficient), human studies were conducted [72, 73]. Wong et al. [72] showed that $\left[{ }^{18} \mathrm{~F}\right] \mathrm{AZAN}$ has a favorable dosimetry $(0.014 \mathrm{mSv} / \mathrm{MBq})$ and rapidly enters the human brain, with maximal regional brain uptake before $20 \mathrm{~min}$ post injection. The binding potential was around 2.5 (slightly better than that of nifene and FA), and specificity was confirmed by full blockage of uptake by the smoking cessation drug varenicline, a selective $\alpha 4 \beta 2$ nAChR partial agonist. In terms of stability, three radiometabolites were found, one of which entered the brain. It remains to be investigated to what extent these would interfere in the peripheral signal.

\section{$\left[{ }^{18}\right.$ F]Flubatine}

$(-)-\left[{ }^{18} \mathrm{~F}\right]$ Flubatine $\left[(-)-\left[{ }^{18} \mathrm{~F}\right]\right.$ norchloro-fluorohomoepibatidine] can be produced with a good yield $(60 \%)$ and high specific activities of $>750 \mathrm{GBq} / \mu \mathrm{mol}[49,50 \bullet \cdot]$. The ligand binds with high affinity and selectivity to the $\alpha 4 \beta 2$ receptor subtype. The tracer is very stable in vivo (nearly $90 \%$ at 90 min post injections) and shows only moderate plasma protein binding $(15 \%)$. Although never tried in vascular imaging, this compound seems feasible for this indication.

Another functional enantiomer, (+)-flubatine, similar in binding characteristics to (-)-flubatine, has a somewhat higher toxicity ( $1.5 \mathrm{vs} .6 .2 \mu \mathrm{g} / \mathrm{kg}$ for the (-) enantiomer). This toxicity is a known problem in epibatine analogues and in the case of $\left[{ }^{18} \mathrm{~F}\right] \mathrm{FPH}$, with an $\mathrm{LD}_{50}$ of $40 \mathrm{nmol} / \mathrm{kg}$, even forced discontinuation of research $[74,75]$.

\section{Current Tracers for $\alpha 7$-nAChRs}

Compared with $\alpha 4 \beta 2$-nAChRs, the $\alpha 7$ receptor is much more difficult to visualize in the human brain, mainly because of its lower expression of about $50 \mathrm{fmol} / \mathrm{mg}$ protein [40]. Similar values were demonstrated in vascular endothelial cells, with expression levels varying between $53 \mathrm{fmol} / \mathrm{mg}$ protein (untreated cells) and $385 \mathrm{fmol} / \mathrm{mg}$ protein (cells exposed to $50-\mu \mathrm{M}$ nicotine). The steric and electronic requirements of the orthosteric agonist-binding site of the $\alpha 7$ receptor are fulfilled by structurally diverse classes of compounds. Currently, the most promising agents for molecular imaging in vivo are the substituted diazabicyclononane derivatives. One of these compounds, $\left[{ }^{11} \mathrm{C}\right] \mathrm{CHIBA}-1001$, has been investigated thoroughly in preclinical and preliminary clinical studies. Similar ${ }^{18} \mathrm{~F}$-labeled compounds also have been quite successful, and the full inventory of currently developed functional radioligands is described in the following text. 
<smiles>Fc1ccc(-c2nnc(N3CCN4CCC3CC4)o2)cc1</smiles>

${ }^{18} \mathrm{~F}$ - NS10743

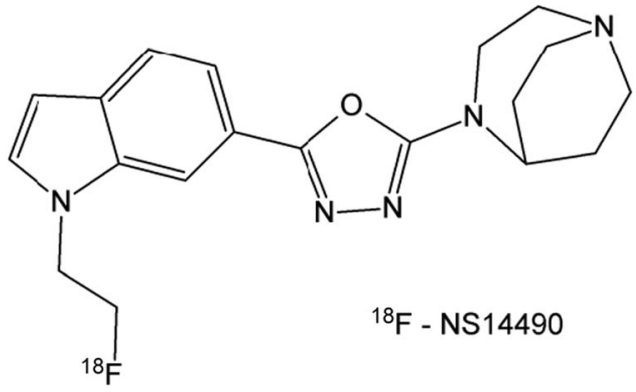<smiles>CNc1ccccc1C(=O)OC1CN2CCC1CC2</smiles>

11C(R)-MeQAA<smiles></smiles>

${ }^{18} \mathrm{~F}$ - ASEM<smiles>Cn1cccc1-c1nnc(N2CCN3CCC2CC3)o1</smiles>

11C - NS14492

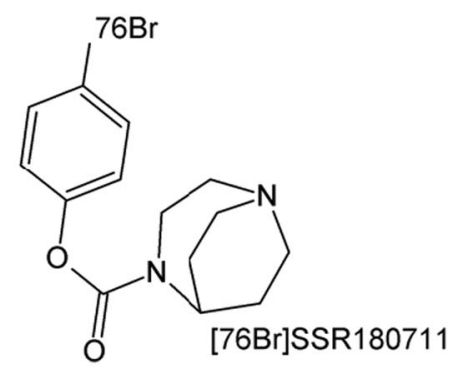<smiles>Cc1ccc(OC(=O)N2CCN3CCC2CC3)cc1</smiles>

[11C]CHIBA - 1001

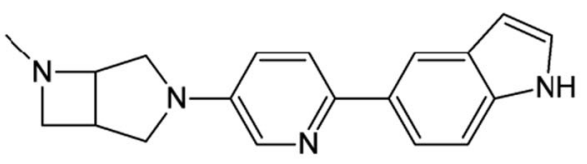

rac - 1<smiles>CN1CC2CN(c3ccc4c(c3)C(=O)c3cc(N5CC6CN(c7ccc(-c8ccc9[nH]ccc9c8)nn7)CC6CN5C)ccc3-4)CC21</smiles>

A - 833834<smiles>CN1CC2CN(c3ccc(-c4ccccc4)nn3)CC2C1</smiles>

A - 582941

A - 752274<smiles>[Y]C1CC2CN(c3ccc4c(c3)C(=O)C3C=CC=CC3O4)CC2C1</smiles> 


\section{$\left[{ }^{11} \mathrm{C}\right] \mathrm{A}-752274$}

$\left[{ }^{11} \mathrm{C}\right] \mathrm{A}-752274$ and $\left[{ }^{11} \mathrm{C}\right] \mathrm{A}-833834$ both were developed by the group of Horti et al. [76]. The radioligands were prepared with a radiochemical yield of 12 to $32 \%$, high specific radioactivity $(300-400 \mathrm{GBq} / \mu \mathrm{mol})$, and radiochemical purity $>95 \%$. Biodistribution studies in mice with $\left[{ }^{11} \mathrm{C}\right] \mathrm{A}-833834$ showed low specific $\alpha 7-\mathrm{nAChR}$ binding in the brain, and although $\left[{ }^{11} \mathrm{C}\right] \mathrm{A}-752274$ specifically $(\sim 50 \%)$ labeled $\alpha 7-\mathrm{nAChR}$ in mouse thalamus, it exhibited low uptake in baboon brain, thereby raising questions about its efficacy.

\section{$\left[{ }^{11} \mathrm{C}\right] \mathrm{A}-582941$ and $\left[{ }^{11} \mathrm{C}\right] \mathrm{A}-844606$}

$\left[{ }^{11} \mathrm{C}\right] \mathrm{A}-582941$ and $\left[{ }^{11} \mathrm{C}\right] \mathrm{A}-844606$ were developed in 2009 by the group of Toyohara et al. [77]. The ligands showed specific uptake in brain regions with high $\alpha 7$ expression; however, they also were unstable, showing rapid formation of two metabolites, rendering these tracers unsuitable for peripheral imaging.

\section{$\left[{ }^{11} \mathrm{C}\right] \mathrm{rac}-(1)$}

$\left[{ }^{11} \mathrm{C}\right] \mathrm{rac}-(1)$ was developed by Gao et al. [78]. The radiosynthesis was accomplished via $N$-methylation of the nor-methyl precursor followed by semipreparative HPLC purification and ${ }^{18} \mathrm{C}$ solid-phase extraction and formulation, resulting in an average yield of $30 \%$, radiochemical purity $>98 \%$, and specific activity of $444 \pm$ $74 \mathrm{GBq} / \mu \mathrm{mol}$. Affinity toward the $\alpha 7-\mathrm{nAChR}$ is about $0.5 \mathrm{nM}$, which allows in vivo use. In the mouse brain, $\left[{ }^{11} \mathrm{C}\right] \mathrm{rac}-(1)$ specifically accumulated in the frontal cortex and hippocampus, regions with an elevated density of $\alpha 7$-nAChRs, whereas uptake in the cerebellum, a region with low $\alpha 7$-nAChR densities, was nonspecific. Further research in monkeys, including in vivo displacement studies, are required before human research is performed, but so far the compound seems promising.

\section{$\left[{ }^{11} \mathrm{C}\right] \mathrm{MeQAA}$}

Compared with some of the previously described ${ }^{11} \mathrm{C}$-labeled compounds, (R)-2-methylamino-benzoic acid 1-azabicyclo[2.2.2] oct-3-yl ester ( $\left.\left[{ }^{11} \mathrm{C}\right] \mathrm{MeQAA}\right)$ is more stable and does not produce any metabolites that enter the brain [79]. This tracer shows an intermediate affinity for the $\alpha 7$ $\mathrm{nAChR}(41 \mathrm{nM})$ in vitro and a (rhesus monkey) brain distribution pattern in vivo that matches the $\alpha 7$ expression distribution, but so far no displacement studies have been performed.

\section{$\left[{ }^{76} \mathrm{Br}\right]$ SSR 180771 and $\left[{ }^{11} \mathrm{C} \mid \mathrm{CHIBA} 1001\right.$}

$\left[{ }^{11} \mathrm{C}\right] \mathrm{CHIBA} 1001$ and its bromide analogue, $\left[{ }^{76} \mathrm{Br}\right] \mathrm{SSR} 180771$, were developed in 2008 by the group of Hashimoto et al. [80-82], with further trials conducted in later years. $\left[{ }^{76} \mathrm{Br}\right] \mathrm{SSR} 180771$ was prepared with an intermediate yield of $17 \%$ and with high radiochemical purity and specific activity (respectively, $100 \%$ and $8 \mathrm{GBq} / \mu \mathrm{mol})$. For $\left[{ }^{11} \mathrm{C}\right] \mathrm{CHIBA} 1001$, the yield was around $10 \%$. Although the affinity of these compounds for $\alpha 7$-nAChR is not optimal $(120-180 \mathrm{nM})$, the uptake of both compounds in rhesus monkeys was fast and matched $\alpha 7$ distribution patterns. Furthermore, the brain uptake could be reduced significantly by using an $\alpha 7$ receptor specific agonist (SSR180771), but not by an $\alpha 4 \beta 2$-receptor specific ligand (A85380), indicating specific uptake. Because of the cost of ${ }^{76} \mathrm{Br}$ and the higher brain uptake of the ${ }^{11} \mathrm{C}$ analogue, preference is given to $\left[{ }^{11} \mathrm{C}\right]$ CHIBA for human research. So far, a limited human study with $\left[{ }^{11} \mathrm{C}\right] \mathrm{CHIBA}$ showed high in vivo plasma stability ( $>80 \%$ at 60 min post injection) and the highest brain distribution volume in the thalamus, although regional differences in brain activity were small [83]. The rather poor affinity of this ligand contraindicates further human research.

\section{$\left[{ }^{18}\right.$ F $]$ NS10743}

$\left[{ }^{18} \mathrm{~F}\right] \mathrm{NS} 10743$ was first reported in 2009 by Deuther-Conrad et al. $[84,85]$, who produced the tracer from a nitro precursor. The specific activity exceeded $150 \mathrm{GBq} / \mu \mathrm{mol}$ at a radiochemical purity $>99 \%$. This tracer showed a relatively high affinity of about $10 \mathrm{nM}$ toward $\alpha 7$ and about $84 \mathrm{nM}$ toward $\alpha 3 \beta 4$ in vitro and partially reduced the cortical and hippocampal binding of tritiated $\alpha$-bungarotoxin ex vivo. In vivo, $\left[{ }^{18} \mathrm{~F}\right] \mathrm{NS} 10743$ showed rapid uptake in mouse brain, which could be reduced by SSR180711, a known specific $\alpha 7$ ligand, thereby proving in vivo specificity.

\section{$\left[{ }^{18}\right.$ F]ASEM}

As a response to poor-affinity ligands such as $\left[{ }^{11} \mathrm{C}\right] \mathrm{CHIBA}$, $\left[{ }^{18} \mathrm{~F}\right]$ ASEM (3-(1,4-diazabicyclo[3.2.2]nonane-4-yl)$6-\left[{ }^{18} \mathrm{~F}\right]$ fluorodibenzo[b,d]thiophene-5,5-dioxide) was designed [86]. In total, the group of Gao et al. [86, 87] developed five ligands, each differing by position of the fluorine atom. Based on in vitro assays and in vivo PET and biodistribution studies, they concluded that $\left[{ }^{18} \mathrm{~F}\right] \mathrm{ASEM}$ (with the ${ }^{18} \mathrm{~F}$ in ortho position from the sulfoxide structure and away from the diazabicyclononane) showed the most promising characteristics for imaging. $\left[{ }^{18} \mathrm{~F}\right] \mathrm{ASEM}$ is produced with a typical yield of about $16 \%$ (non-decay-corrected) and shows a specific activity of $300-1200 \mathrm{GBq} / \mu \mathrm{mol}$ and $>99 \%$ radiochemical 
purity. Care must be taken during the purification process: HPLC is required to remove the nitro precursors completely, as they also have a high affinity toward the $\alpha 7$ receptor. The radioligand itself is characterized by a subnanomolar affinity toward $\alpha 7$-nAChR $(0.4 \mathrm{nM})$ and a very high selectivity compared with other nicotinergic receptors [86, 87]. In vivo, the brain distribution pattern in mice matched that of known $\alpha 7$ receptor expression and could be decreased significantly by SSR180771. So far, no human research has been performed with this ligand, although it appears promising for vascular research.

\section{$\left[{ }^{18} \mathrm{~F}\right] \mathrm{NS} 14490$ and $\left[{ }^{11} \mathrm{C}\right] \mathrm{NS} 14492$}

$\left[{ }^{18} \mathrm{~F}\right] \mathrm{NS} 14490$ and $\left[{ }^{11} \mathrm{C}\right] \mathrm{NS} 14492$, developed by the group of Brust et al. [54••, 55, 88], can be synthesized with a $70 \%$ yield and show a good affinity toward $\alpha 7$-nAChR (about $2.5 \mathrm{nM}$ ). Sadly, however, brain uptake is rather low in mice, casting doubt about their utility for brain research.

Although human data showed mediocre applicability of this ligand for brain $\alpha 7$-nAChR imaging, imaging of vascular $\alpha 7$-nAChRs has proven feasible [54••]. The mediocre $\alpha 7$ binding in the brain may be the result of poor BBB permeation or perhaps of efflux processes by P-glycoprotein, features less relevant when imaging in the periphery $[54 \bullet \bullet, 55]$.

\section{Conclusions}

During the past several years, interest has been growing in the use of nAChRs for diagnosing as well as treating neurologic, oncologic, and vascular disorders. Specific imaging of neuronal and non-neuronal nAChRs therefore is crucial, and PET imaging offers a noninvasive and easily applicable methodology. Although several nAChR PET tracers are available today, most are still in preclinical evaluation or in clinical evaluation for imaging of cerebral nAChRs in the context of neurodegenerative disorders. However, initial attempts have been made to apply these tracers to the imaging of non-neuronal $\alpha 7$ - and $\alpha 4 \beta 2$-nAChRs in the cardiovascular system. The results of these feasibility studies, both in humans and in the experimental setting, show great promise, so further steps toward clinical implementation of in vivo vascular nAChR PET imaging in atherosclerosis should be taken. Therefore, research is under way to further evaluate the tracers available for clinical imaging of non-neuronal nAChRs, particularly in patients with known atherosclerosis in the carotid but also in the coronary arteries, and to develop new PET tracers for different $\mathrm{nAChRs}$, with the goal of proving the feasibility of $\mathrm{nAChR}$ PET imaging in the clinical context.

\section{Compliance with Ethics Guidelines}

Conflict of Interest Matthias Bauwens, Felix M. Mottaghy, and Jan Bucerius declare that they have no conflict of interest.

Human and Animal Rights and Informed Consent This article does not contain any studies with human or animal subjects performed by any of the authors.

Open Access This article is distributed under the terms of the Creative Commons Attribution 4.0 International License (http://creativecommons.org/licenses/by/4.0/), which permits unrestricted use, distribution, and reproduction in any medium, provided you give appropriate credit to the original author(s) and the source, provide a link to the Creative Commons license, and indicate if changes were made.

\section{References}

Papers of particular interest, published recently, have been highlighted as:

•- Of major importance

1. Tarkin JM, Rudd JH. Techniques for noninvasive molecular imaging of atherosclerotic plaque. Nat Rev Cardiol. 2014;12(2):79.

2. Nichols M, Townsend N, Scarborough P, Rayner M. Cardiovascular disease in Europe 2014: epidemiological update. Eur Heart J. 2014;35(42):2950-9.

3. Lozano R, Naghavi M, Foreman K, et al. Global and regional mortality from 235 causes of death for 20 age groups in 1990 and 2010: a systematic analysis for the Global Burden of Disease Study 2010. Lancet. 2012;380(9859):2095-128.

4.• Santanam N, Thornhill BA, Lau JK, et al. Nicotinic acetylcholine receptor signaling in atherogenesis. Atherosclerosis. 2012;225(2): 264-73. This recent review of $\mathbf{n A C h R s}$ in atherosclerosis summarizes the proatherogenic effects mediated by vascular nAChRs and discusses the pathophysiologic effects of different nAChR subunits in plaque growth, progression, and neovascularization.

5. Clinton SK, Underwood R, Hayes L, Sherman ML, Kufe DW, Libby P. Macrophage colony-stimulating factor gene expression in vascular cells and in experimental and human atherosclerosis. Am J Pathol. 1992;140(2):301-16.

6. Doyle B, Caplice N. Plaque neovascularization and antiangiogenic therapy for atherosclerosis. J Am Coll Cardiol. 2007;49(21):207380.

7. Egleton RD, Brown KC, Dasgupta P. Angiogenic activity of nicotinic acetylcholine receptors: implications in tobacco-related vascular diseases. Pharmacol Ther. 2009;121(2):205-23.

8. Lindstrom J. Nicotinic acetylcholine receptors in health and disease. Mol Neurobiol. 1997;15(2):193-222.

9. Itier V, Bertrand D. Neuronal nicotinic receptors: from protein structure to function. FEBS Lett. 2001;504(3):118-25.

10. Gotti C, Clementi F. Neuronal nicotinic receptors: from structure to pathology. Prog Neurobiol. 2004;74(6):363-96.

11. Lukas RJ. Heterogeneity of high-affinity nicotinic $[3 \mathrm{H}]$ acetylcholine binding sites. J Pharmacol Exp Ther. 1990;253(1):51-7.

12. Glowatzki E, Fuchs PA. Cholinergic synaptic inhibition of inner hair cells in the neonatal mammalian cochlea. Science. 2000;288(5475):2366-8. 
13. Schmaljohann J, Gundisch D, Minnerop M, et al. A simple and fast method for the preparation of n.c.a. 2-[18F]F-A85380 for human use. Appl Radiat Isot. 2005;63(4):433-5

14. Schmaljohann J, Gundisch D, Minnerop M, et al. In vitro evaluation of nicotinic acetylcholine receptors with 2-[18F]F-A85380 in Parkinson's disease. Nucl Med Biol. 2006;33(3):305-9.

15. Kendziorra K, Wolf H, Meyer PM, et al. Decreased cerebral alpha4beta2* nicotinic acetylcholine receptor availability in patients with mild cognitive impairment and Alzheimer's disease assessed with positron emission tomography. Eur J Nucl Med Mol Imaging. 2010;38(3):515-25.

16. Wada T, Naito M, Kenmochi H, Tsuneki H, Sasaoka T. Chronic nicotine exposure enhances insulin-induced mitogenic signaling via up-regulation of alpha7 nicotinic receptors in isolated rat aortic smooth muscle cells. Endocrinology. 2007;148(2):790-9.

17. Albaugh G, Bellavance E, Strande L, Heinburger S, Hewitt CW, Alexander JB. Nicotine induces mononuclear leukocyte adhesion and expression of adhesion molecules, VCAM and ICAM, in endothelial cells in vitro. Ann Vasc Surg. 2004;18(3):302-7.

18. Schedel A, Thornton S, Schloss P, Kluter H, Bugert P. Human platelets express functional alpha7-nicotinic acetylcholine receptors. Arterioscler Thromb Vasc Biol. 2010;31(4):928-34.

19. Zhang G, Kernan KA, Thomas A, et al. A novel signaling pathway: fibroblast nicotinic receptor alphal binds urokinase and promotes renal fibrosis. J Biol Chem. 2009;284(42):29050-64.

20. Tithof PK, Elgayyar M, Schuller HM, Barnhill M, Andrews R. 4(methylnitrosamino)-1-(3-pyridyl)-1-butanone, a nicotine derivative, induces apoptosis of endothelial cells. Am J Physiol Heart Circ Physiol. 2001;281(5):H1946-54.

21. Dasgupta P, Chellappan SP. Nicotine-mediated cell proliferation and angiogenesis: new twists to an old story. Cell Cycle. 2006;5(20):2324-8.

22. Shin VY, Wu WK, Chu KM, et al. Functional role of betaadrenergic receptors in the mitogenic action of nicotine on gastric cancer cells. Toxicol Sci. 2007;96(1):21-9.

23. Li S, Zhao T, Xin H, et al. Nicotinic acetylcholine receptor alpha7 subunit mediates migration of vascular smooth muscle cells toward nicotine. J Pharmacol Sci. 2004;94(3):334-8.

24. Di Luozzo G, Pradhan S, Dhadwal AK, Chen A, Ueno H, Sumpio BE. Nicotine induces mitogen-activated protein kinase dependent vascular smooth muscle cell migration. Atherosclerosis. 2005;178(2):271-7.

25. Kanda Y, Watanabe Y. Nicotine-induced vascular endothelial growth factor release via the EGFR-ERK pathway in rat vascular smooth muscle cells. Life Sci. 2007;80(15):1409-14.

26. Stein JJ, Seymour KA, Maier KG, Gahtan V. The effects of nicotine on vascular smooth muscle cell chemotaxis induced by thrombospondin-1 and fibronectin. Am J Surg. 2011;202(5):545-8.

27. Cucina A, Fuso A, Coluccia P, Cavallaro A. Nicotine inhibits apoptosis and stimulates proliferation in aortic smooth muscle cells through a functional nicotinic acetylcholine receptor. J Surg Res. 2008;150(2):227-35.

28. Heeschen C, Jang JJ, Weis M, et al. Nicotine stimulates angiogenesis and promotes tumor growth and atherosclerosis. Nat Med. 2001;7(7):833-9.

29. Lee J, Cooke JP. The role of nicotine in the pathogenesis of atherosclerosis. Atherosclerosis. 2011;215(2):281-3.

30. Vazquez-Padron RI, Mateu D, Rodriguez-Menocal L, Wei Y, Webster KA, Pham SM. Novel role of Egr-1 in nicotine-related neointimal formation. Cardiovasc Res. 2010;88(2):296-303.

31. Jacob T, Clouden N, Hingorani A, Ascher E. The effect of cotinine on telomerase activity in human vascular smooth muscle cells. J Cardiovasc Surg (Torino). 2009;50(3):345-9.

32. MacLellan WR, Wang Y, Lusis AJ. Systems-based approaches to cardiovascular disease. Nat Rev Cardiol. 2012;9(3):172-84.
33. Cucina A, Sapienza P, Corvino V, et al. Nicotine-induced smooth muscle cell proliferation is mediated through $\mathrm{bFGF}$ and TGF-beta 1. Surgery. 2000;127(3):316-22.

34. Cucina A, Sapienza P, Corvino V, et al. Nicotine induces plateletderived growth factor release and cytoskeletal alteration in aortic smooth muscle cells. Surgery. 2000;127(1):72-8.

35. Cooke JP, Ghebremariam YT. Endothelial nicotinic acetylcholine receptors and angiogenesis. Trends Cardiovasc Med. 2008;18(7): 247-53.

36. Wu JC, Chruscinski A, De Jesus Perez VA, et al. Cholinergic modulation of angiogenesis: role of the 7 nicotinic acetylcholine receptor. J Cell Biochem. 2009;108(2):433-46.

37. Stylianou IM, Bauer RC, Reilly MP, Rader DJ. Genetic basis of atherosclerosis: insights from mice and humans. Circ Res. 2012;110(2):337-55.

38. Aicher A, Heeschen C, Mohaupt M, Cooke JP, Zeiher AM, Dimmeler S. Nicotine strongly activates dendritic cell-mediated adaptive immunity: potential role for progression of atherosclerotic lesions. Circulation. 2003;107(4):604-11.

39. Antoni G, Langstrom B. Radiopharmaceuticals: molecular imaging using positron emission tomography. Handb Exp Pharmacol. 2008;(185 Pt 1):177-201.

40. Brust P, Peters D, Deuther-Conrad W. Development of radioligands for the imaging of alpha7 nicotinic acetylcholine receptors with positron emission tomography. Curr Drug Targets. 2012;13(5): 594-601.

41. Hagooly A, Rossin R, Welch MJ. Small molecule receptors as imaging targets. Handb Exp Pharmacol. 2008;(185 Pt 2):93-129.

42. Heiss WD, Herholz K. Brain receptor imaging. J Nucl Med. 2006;47(2):302-12.

43. Spanoudaki VC, Ziegler SI. PET \& SPECT instrumentation. Handb Exp Pharmacol. 2008;(185 Pt 1):53-74.

44. Galban CJ, Galban S, Van Dort ME, et al. Applications of molecular imaging. Prog Mol Biol Transl Sci. 2010;95:237-98.

45. Xi W, Tian M, Zhang H. Molecular imaging in neuroscience research with small-animal PET in rodents. Neurosci Res. 2011;70(2):133-43.

46. Lancelot S, Zimmer L. Small-animal positron emission tomography as a tool for neuropharmacology. Trends Pharmacol Sci. 2010;31(9):411-7.

47. Heiss WD, Habedank B, Klein JC, et al. Metabolic rates in small brain nuclei determined by high-resolution PET. J Nucl Med. 2004;45(11):1811-5.

48. Lecomte R. Novel detector technology for clinical PET. Eur J Nucl Med Mol Imaging. 2009;36 Suppl 1:S69-85.

49. Sattler B, Kranz M, Starke A, Wilke S, Donat CK, Deuther-Conrad $\mathrm{W}$, et al. Internal dose assessment of (-)-18F-flubatine, comparing animal model datasets of mice and piglets with first-in-human results. J Nucl Med. 2014;55(11):1885-92.

50.• Patt M, Becker GA, Grossmann U, et al. Evaluation of metabolism, plasma protein binding and other biological parameters after administration of $(-)-[(18) F]$ Flubatine in humans. Nucl Med Biol. 2014;41(6):489-94. In this paper, Patt et al. demonstrate the applicability of $(-)-\left[{ }^{18} \mathrm{~F}\right.$ ]flubatine in visualization of (brain) $\alpha 4 \beta 2$ receptor in humans.

51. Smits R, Fischer S, Hiller A, et al. Synthesis and biological evaluation of both enantiomers of [(18)F]flubatine, promising radiotracers with fast kinetics for the imaging of alpha4beta2-nicotinic acetylcholine receptors. Bioorg Med Chem. 2013;22(2):804-12.

52. Fischer S, Hiller A, Smits R, et al. Radiosynthesis of racemic and enantiomerically pure $(-)-[18 \mathrm{~F}]$ flubatine - a promising PET radiotracer for neuroimaging of alpha4beta2 nicotinic acetylcholine receptors. Appl Radiat Isot. 2013;74:128-36.

53. Brust P, van den Hoff J, Steinbach J. Development of (18)F-labeled radiotracers for neuroreceptor imaging with positron emission tomography. Neurosci Bull. 2014;30(5):777-811. 
54.• Rötering S, Deuther-Conrad W, Cumming P, et al. Imaging of alpha7 nicotinic acetylcholine receptors in brain and cerebral vasculature of juvenile pigs with [(18)F]NS14490. EJNMMI Res. $2014 ; 4: 43$. In this publication, the authors show that $\alpha 7$ nAChR tracers, although developed for imaging in the brain, also may be used to visualize vascular acetylcholine receptor.

55. Rötering S, Scheunemann M, Fischer S, et al. Radiosynthesis and first evaluation in mice of [(18)F]NS14490 for molecular imaging of alpha7 nicotinic acetylcholine receptors. Bioorg Med Chem. 2013;21(9):2635-42.

56. Bucerius J, Joe AY, Schmaljohann J, et al. Feasibility of 2-deoxy-2[18F]fluoro-D-glucose- A85380-PET for imaging of human cardiac nicotinic acetylcholine receptors in vivo. Clin Res Cardiol. 2006;95(2):105-9.

57.• Bucerius J, Manka C, Schmaljohann J, et al. Feasibility of [18F]-2Fluoro-A85380-PET imaging of human vascular nicotinic acetylcholine receptors in vivo. JACC Cardiovasc Imaging. 2012;5(5): 528-36. This is the first publication to show the feasibility of using PET imaging in vivo to detect human vascular nAChRs noninvasively.

58. Cooke JP. Imaging vascular nicotine receptors: a new window onto vascular disease. JACC Cardiovasc Imaging. 2012;5(5):537-9.

59. Kadir A, Almkvist O, Wall A, Langstrom B, Nordberg A. PET imaging of cortical $11 \mathrm{C}$-nicotine binding correlates with the cognitive function of attention in Alzheimer's disease. Psychopharmacology (Berlin). 2006;188(4):509-20.

60. Kadir A, Darreh-Shori T, Almkvist O, et al. PET imaging of the in vivo brain acetylcholinesterase activity and nicotine binding in galantamine-treated patients with AD. Neurobiol Aging. 2008;29(8):1204-17.

61. Kadir A, Darreh-Shori T, Almkvist O, Wall A, Langstrom B, Nordberg A. Changes in brain 11C-nicotine binding sites in patients with mild Alzheimer's disease following rivastigmine treatment as assessed by PET. Psychopharmacology (Berlin). 2007;191(4): 1005-14.

62. Nordberg A, Hartvig P, Lilja A, et al. Decreased uptake and binding of 11C-nicotine in brain of Alzheimer patients as visualized by positron emission tomography. J Neural Transm Park Dis Dement Sect. 1990;2(3):215-24

63. Pichika R, Easwaramoorthy B, Collins D, et al. Nicotinic alpha4beta2 receptor imaging agents: part II. Synthesis and biological evaluation of 2-[18F]fluoro-3-[2-((S)-3-pyrrolinyl)methoxy]pyridine (18Fnifene) in rodents and imaging by PET in nonhuman primate. Nucl Med Biol. 2006;33(3):295-304.

64. Pichika R, Easwaramoorthy B, Christian BT, et al. Nicotinic alpha4beta2 receptor imaging agents. Part III. Synthesis and biological evaluation of 3-(2-(S)-azetidinylmethoxy)-5-(3'-18Ffluoropropyl)pyridine (18F-nifzetidine). Nucl Med Biol. 2011;38(8):1183-92.

65. Pichika R, Kuruvilla SA, Patel N, et al. Nicotinic alpha4beta2 receptor imaging agents. Part IV. Synthesis and biological evaluation of 3-(2-(S)-3,4-dehydropyrrolinyl methoxy)-5-(3'-(1)(8)Ffluoropropyl)pyridine ((1)(8)F-Nifrolene) using PET. Nucl Med Biol. 2012;40(1):117-25.

66. Mukhin AG, Kimes AS, Chefer SI, et al. Greater nicotinic acetylcholine receptor density in smokers than in nonsmokers: a PET study with 2-18F-FA-85380. J Nucl Med. 2008;49(10):1628-35.

67. Staley JK, van Dyck CH, Weinzimmer D, et al. 123I-5-IA-85380 SPECT measurement of nicotinic acetylcholine receptors in human brain by the constant infusion paradigm: feasibility and reproducibility. J Nucl Med. 2005;46(9):1466-72.

68. Ogawa M, Tsukada H, Hatano K, Ouchi Y, Saji H, Magata Y. Central in vivo nicotinic acetylcholine receptor imaging agents for positron emission tomography (PET) and single photon emission computed tomography (SPECT). Biol Pharm Bull. 2009;32(3): $337-40$.

69. Valette H, Xiao Y, Peyronneau MA, et al. 18F-ZW-104: a new radioligand for imaging neuronal nicotinic acetylcholine receptors - in vitro binding properties and PET studies in baboons. J Nucl Med. 2009;50(8):1349-55.

70. Gao Y, Kuwabara H, Spivak CE, et al. Discovery of (-)-7-methyl2-exo-[3'-(6-[18F]fluoropyridin-2-yl)-5'-pyridinyl]-7azabicyclo[2.2.1] heptane, a radiolabeled antagonist for cerebral nicotinic acetylcholine receptor (alpha4beta2-nAChR) with optimal positron emission tomography imaging properties. J Med Chem. 2008;51(15):4751-64.

71. Horti AG, Gao Y, Kuwabara H, Dannals RF. Development of radioligands with optimized imaging properties for quantification of nicotinic acetylcholine receptors by positron emission tomography. Life Sci. 2008;86(15-16):575-84.

72. Wong DF, Kuwabara H, Kim J, et al. PET imaging of high-affinity alpha4beta2 nicotinic acetylcholine receptors in humans with $18 \mathrm{~F}$ AZAN, a radioligand with optimal brain kinetics. J Nucl Med. 2013;54(8):1308-14.

73. Meyer PM, Tiepolt S, Barthel H, Hesse S, Sabri O. Radioligand imaging of alpha4beta $2 *$ nicotinic acetylcholine receptors in Alzheimer's disease and Parkinson's disease. Q J Nucl Med Mol Imaging. 2014;58(4):376-86.

74. Villemagne VL, Horti A, Scheffel U, et al. Imaging nicotinic acetylcholine receptors with fluorine-18-FPH, an epibatidine analog. J Nucl Med. 1997;38(11):1737-41.

75. Horti AG, Chefer SI, Mukhin AG, et al. 6-[18F]fluoro-A-85380, a novel radioligand for in vivo imaging of central nicotinic acetylcholine receptors. Life Sci. 2000;67(4):463-9.

76. Horti AG, Ravert HT, Gao Y, et al. Synthesis and evaluation of new radioligands [(11)C]A-833834 and [(11)C]A-752274 for positronemission tomography of alpha7-nicotinic acetylcholine receptors. Nucl Med Biol. 2013;40(3):395-402.

77. Toyohara J, Ishiwata K, Sakata M, et al. In vivo evaluation of alpha7 nicotinic acetylcholine receptor agonists [11C]A-582941 and [11C]A-844606 in mice and conscious monkeys. PLoS One. 2010;5(2):e8961.

78. Gao Y, Ravert HT, Valentine H, et al. 5-(5-(6-[(11)C]methyl-3,6diazabicyclo[3.2.0]heptan-3-yl)pyridin-2-yl)-1H-indole as a potential PET radioligand for imaging cerebral alpha7-nAChR in mice. Bioorg Med Chem. 2012;20(12):3698-702.

79. Ogawa M, Nishiyama S, Tsukada H, et al. Synthesis and evaluation of new imaging agent for central nicotinic acetylcholine receptor alpha7 subtype. Nucl Med Biol. 2010;37(3):347-55.

80. Sakata $\mathrm{M}, \mathrm{Wu} \mathrm{J}$, Toyohara $\mathrm{J}$, et al. Biodistribution and radiation dosimetry of the alpha7 nicotinic acetylcholine receptor ligand [11C]CHIBA-1001 in humans. Nucl Med Biol. 2011;38(3):443-8.

81. Wu J, Toyohara J, Tanibuchi Y, et al. Pharmacological characterization of [(125)I]CHIBA-1006 binding, a new radioligand for alpha7 nicotinic acetylcholine receptors, to rat brain membranes. Brain Res. 2010;1360:130-7.

82. Hashimoto K, Ishima T, Fujita Y, et al. Phencyclidine-induced cognitive deficits in mice are improved by subsequent subchronic administration of the novel selective alpha7 nicotinic receptor agonist SSR180711. Biol Psychiatry. 2008;63(1):92-7.

83. Toyohara J, Sakata M, Wu J, et al. Preclinical and the first clinical studies on [11C]CHIBA-1001 for mapping alpha7 nicotinic receptors by positron emission tomography. Ann Nucl Med. 2009;23(3): 301-9.

84. Deuther-Conrad W, Fischer S, Hiller A, et al. Assessment of alpha7 nicotinic acetylcholine receptor availability in juvenile pig brain 
with [(1)(8)F]NS10743. Eur J Nucl Med Mol Imaging. 2011;38(8): 1541-9.

85. Deuther-Conrad W, Fischer S, Hiller A, et al. Molecular imaging of alpha7 nicotinic acetylcholine receptors: design and evaluation of the potent radioligand $[18 \mathrm{~F}] \mathrm{NS} 10743$. Eur J Nucl Med Mol Imaging. 2009;36(5):791-800.

86. Wong DF, Kuwabara H, Pomper M, et al. Human brain imaging of alpha7 nAChR with [(18)F]ASEM: a new PET radiotracer for neuropsychiatry and determination of drug occupancy. Mol Imaging Biol. 2014;16(5):730-8.

87. Gao Y, Kellar KJ, Yasuda RP, et al. Derivatives of dibenzothiophene for positron emission tomography imaging of alpha7-nicotinic acetylcholine receptors. J Med Chem. 2013;56(19):7574-89.

88. Ettrup A, Mikkelsen JD, Lehel S, et al. 11C-NS14492 as a novel PET radioligand for imaging cerebral alpha 7 nicotinic acetylcholine receptors: in vivo evaluation and drug occupancy measurements. J Nucl Med. 2011;52(9):1449-56.

89. Rötering S, Deuther-Conrad W, Cumming P, et al. Imaging of $\alpha 7$ nicotinic acetylcholine receptors in brain and cerebral vasculature of juvenile pigs with [18F] NS14490. EJNMMI Res. 2014;4:43. 